\title{
LA ENCRUCIJADA, A EXAMEN
}

\author{
POR
}

J.A.G.

Hispania Sacra

Massimo BORGHESI: Posmodernidad y cristianismo: ¿Una radical mutación antropolbgica?, Madrid, Ediciones Encuentro, 1997,230 págs.

Angel DAVID MARTíN RUBIO: La persecución religiosa en Extremadura durante la Guerra civil (1936-1939), Badajoz, Asociación Cultural Carlos V, 1996, 139 págs.

Luis de LLERA ESTEBAN (coord.): El úttimo exilio español en América, Madrid, Editorial Mapfre, 780 págs.

Justo Formentín IBÁN̄ez; María José VILlegas SanZ: La Escuela de Párvulos de Simancas, un ensayo pedagógico de la Junta para Ampliación de Estudios, Madrid, Consejo Superior de Investigaciones Científicas, 1996, 315 págs.

Alfonso AlVARez BOLADO: Para ganar la guerra, para ganar la paz, Madrid, Universidad Pontificia Comillas, 1995, 716 págs.

Francisco VERDERA: Conflictos entre la Iglesia y el Estado en Espania: La revista 'Ecclesia' entre 1941 y 1945, Pamplona, Eunsa, 1995, 272 págs.

José María SALAVERRI, Santiago Gapp: Pasión por la verdad frente al nazismo, Madrid, PPC, 1996, 237 págs.

Colm Tóíín: La seftal de la cruz: Viaje al fondo del catolicismo europeo, Madrid, Anaya \& Mario Muchnik, 1996, 295 págs.

Ramiro VIOLA GONZÁlEZ: Historia de la congregación de carmelitas misioneras teresianas, t. II: El Carmelo Misionero Teresiano: Raíces y carisma, Burgos, Imprenta Monte Carmelo, 1995, 933 págs.

José Antonio MARCELLÁN EIGORRI: La Iglesia navarra, a los cuatro vientos, 1936-1986, Pamplona, Ediciones Eunate, 1996,667 págs.

Vicente ENRIQUE Y TARANCón: Confesiones, Madrid, PPC, 1996, 923 págs.

Clarividente. Luego pondremos un único pero. Mas, como punto de partida, ése es el adjetivo que merece lo escrito por Massimo Borghesi. La tesis es ésta: nadie puede hacerse

La Iglesia en la Encrucijada Hispania Sacra 49 (1997) 
ilusiones sobre el retorno a lo espiritual, incluso a lo religioso, que se da en Occidente en nuestros días, porque las bases antropológicas de ese retomo no sólo no son cristianas - no digamos católicas - sino que son profundamente anticristianas. $Y$ esto es así porque se trata de una religiosidad inmanentista, referida al sí mismo, a la búsqueda de Dios en el yo, y eso es hegeliano y no cristianismo. De hecho, el cristianismo irrita - hoy- cuando se plantea como algo más que como un aliado para la defensa de una moral (mejor: de unos aspectos de la moral) y de unos valores. Es decir: se acepta en la medida en que sirve, pragmáticamente, para coadyuvar a la convivencia, no en el momento en que asegura que el Hijo de Dios se hizo carne y que, como consecuencia de ello y no por otra razón, adoptamos unos comportamientos morales.

El libro dice desde luego mucho más: no se limita a criticar esa reducción moralista y a poner de relieve la profunda contradicción entre cristianismo y esa posmodemidad de moral de consensus, sino que pasa a analizar la respuesta que domina entre los católicos. Y el resultado es éste, según el autor: hemos vivido en la onda propuesta por León XIII de defender la ley natural y, con ella, el derecho natural; así hasta los años ochenta. Y con ello no hemos hecho sino precisamente reducir el cristianismo a defensa de valores y de comportamientos morales compartidos, por lo menos en la medida en que los católicos no han hablado ademas y sobre todo de que el punto de arranque de esa defensa es el hecho insólito que va de la Encarnación a la Resurrección. Y sus consecuencias.

$\mathrm{Y}$ el resultado no podía ser sino el que ha sido: ahora preguntan ¿y en qué se basa la ley natural?, ¿quién tiene potestad de definirla? Ante lo cual los católicos solo pueden responder mirando al papa y los obispos, o sea a la Encarnación y Resurrección.

Pues tomemos por la calle de en medio - viene a decir el autor, sin decirlo- y partamos de este supuesto.

Y aquí viene a incidir otro hecho principal de las últimas décadas, que es la asunción, por parte de los católicos, especialmente de los eclesiásticos, de la lectura protestante (de Bultmann sobre todo) del Nuevo Testamento en clave simbólica. Si es una narración simbólica y no una narración veraz _- en el sentido que tiene en castellano el adjetivo "veraz"--, no podemos partir de la Encarnación, que a lo mejor también fue simbólica.

¿Cuál es la limitación de que hablaba al principio? Únicamente ésta: la de presuponer, aparentemente, que todo en la Jglesia y fuera de ella se apoya en estos supuestos cultos. El autor no concede - no se plantea el concederlo- la posibilidad de que haya muchos católicos, muchos cristianos, que, incluso sin darse cuenta de la trascendencia de lo que hacen, se apoyen en el hecho de la Encarnación y Resurrección para regir sus vidas. Es decir: puede hablarse de las raíces profundamente anticristianas de ese pensamiento concreto que se ha dado en llamar posmoderno, incluso de que ese pensamiento informa el comportamiento de elementos políticos principales (aquí los dirigentes norteamericanos a la cabeza), pero no, sin más, de que la sociedad se asiente en bases anticristianas. Probablemente, siguen salvándonos los santos. En el fondo vengo a decir que la sociedad no sólo la rigen los filosofos.

Desde el punto de vista histórico, de esto nos interesan varias cosas, es obvio. Pero hay una que Borghesi no tiene por qué plantearse: ¿qué ha tenido que ver todo esto con la descristianización de Occidente en el último siglo y medio?, ¿en qué medida ha sido fruto de una estrategia equivocada (la del derecho natural) y en cuál no? Apenas en una línea el autor dice algo que atañe a estas preguntas: pudo ser una estrategia acertada mientras la sociedad era capaz de responder al fondo común eticocristiano, porque mantenía vivo el

La Iglesia en la Encrucijada Hispania Sacra 49 (1997) 
recuerdo de lo que había aprendido alguna vez, en el catecismo, y no negaba la principal, que es la objetividad de la ley natural.

Pero entonces, ¿por qué a pesar de todo ha habido descristianizacion? ¿ $\mathrm{O}$ hemos confundido descristianizacion con desacralización de las costumbres? En parte, sin duda. Pero lo cierto es que ahora se aceptan socialmente actitudes (la abortista, por ejemplo) que homorizaban hace un siglo. Ha habido, pues, algo más que una desacralización de las costumbres. Ha habido una difusión histórica de comportamientos anticristianos. Ahora bien, ¿qué tiene ello que ver con las "estrategias" de los católicos? ¿En qué medida han ayudado a que ocurra asi? A esto el autor no responde; parece dar como seguro que ha sido justamente ta estrategia de la ley natural. ¿Pero puede afirmarse tal cosa?

El libro, ya se ve, vale la pena de la lectura y de la reflexión, también desde el punto de vista de los historiadores.

$\mathrm{Y}$ es que la encrucijada del siglo $\mathrm{XX}$ sigue constituyendo una de las grandes interrogantes de la historia de la Iglesia por la envergadura de lo ocurrido y por la implicación de factores múltiples y diversos, muchos de ellos sumamente relevantes. El grupo de estudios que se recogen aqui, bajo este epígrafe (La Iglesia en la encrucijada), en Hispania Sacra, son una muestra de ello. Lo es también el sinfin de libros y estudios que el asunto continúa provocando.

El de Martín Rubio sobre la persecución religiosa en Extremadura es otro buen ejemplo. Martín Rubio ya ha dado a conocer desde las páginas de Hispania Sacra algo del sistemático estudio que ha emprendido de la persecución religiosa en la España de 1936-1939, intentando superar las ya ricas conclusiones del libro clásico de Montero. Vuelve sobre ello en este mismo volumen de nuestra revista.

Pues bien, en el libro a que nos referimos da un paso adelante con un buen examen del asunto en Extremadura; para ser más exactos, en Badajoz y su provincia; porque la persecución fue mucho menor en la de Cáceres, sencillamente porque cayó del bando nacional casi en su totalidad enseguida del alzamiento.

El autor pasa revista a la bibliografia de la época; enmarca la persecución en su contex to político e ideológico; hace unas valoraciones cuantitativas de conjunto y pasa luego a estudiar lo sucedido en cada partido judicial. Los relatos, expuestos con neutralidad, alcanzan sin embargo límites escalofriantes en alguna ocasion por la brutalidad de lo que relatan. Ved por ejemplo la página 77.

La última parte del libro es un catálogo de las víctimas eclesíasticas; no se contemplan los seglares aunque el autor dice desde el principio que debieron ser muchos, quizá más que los eclesiásticos. E1 estudio está basado en los legajos correspondientes de la Causa General que se conservan en la Sección Guerra civil del Archivo Histórico Nacional, en Salamanca. También, en bibliografía.

No es cosa muy sabida que ese mismo fenómeno, la anarquía generada en la zona republicana en el verano y el otoño de 1936 fue la primera causa del exilio, al que se ha dedicado el grueso volumen, dirigido por Luis de Llera, cuyo título encabeza estas líneas. Se trata de uno de los libros que cierran las Colecciones Mapfre 1492, de las que no parece exagerado decir que han constituido una de las principales aportaciones bibliográficas, si no la principal, hechas con ocasión del V Centenario. Basta decir que el grueso de las Colecciones (doscientos diez libros) se publicó en el mismo affo 1992 y que fueron donadas en su integridad a más de trescientos centros universitarios o de investigación tanto del mundo 
hispano (incluidas por tanto las Filipinas y desde luego toda América) como del mundo del hispanismo.

En los años siguientes se han ido añadiendo varios volúmenes más, hasta acercar las Colecciones a los doscientos cincuenta, y ahora se cierran, con este libro y cuatro más acerca de diversos aspectos de América y el Mogreb. (Las Colecciones incluían dentro del mundo hispano, con sobrada razón, el norte de África, tan vinculado a nuestro mundo ' durante siglos, además de la historia sefardí.)

Las Colecciones eran tales porque ese gran conjunto de libros se distribuyeron en una decena de series, que agruparon los volúmenes temáticamente. Una de ellas se refería a diversos aspectos de la vida iberoamericana y en ella ha encontrado cabida este libro.

El coordinador es conocido por sus estudios acerca de la filosofia y la cultura política española de los siglos XIX y XX; ya ha publicado cosas relacionadas con personalidades del exilio y aquí desarrolla algunas tesis fundamentales. Una nos ha llamado ya la atención en otras ocasiones y es que el exilio intelectual fue sobre todo asunto de 1936 y no de 1939. Dicho de otra manera, los sabios que dejaron España no lo hicieron por la derrota de la República, sino por la desaparición de las garantías de convivencia en los dos frentes de batalla: primero en el republicano, de cuya anarquía huyeron en un principio, y seguidamente del franquismo, de cuyas intenciones represoras desconfiaron con razón.

En realidad, en este volumen, más que el coordinador, quien desarrolla esa tesis es Milagrosa Romero Samper, que traza una acabada imagen de lo que fue el exilio para estos hombres principales. Examina la naturaleza del hecho, la de su instalación en América, el hecho mismo de la salida y el trasiego por el Nuevo Mundo y las actitudes del Gobiemo de la república en el exilio, completamente desbordado por la realidad de la avalancha y también por las diferencias políticas que había entre los exiliados.

Siguen varios capítulos temáticos, concretamente acerca de tres aspectos especialmente relevantes: el exilio de los escritores, el de los filosofos y el de los científicos y los artistas. De los escritores se encarga Rosa María Grillo. Examina los exiliados según el género literario que practicaban y la actividad editorial, deteniéndose especialmente en quienes cultivaron lenguas distintas del castellano: gallegos, vascos y catalanes.

Del exilio filosofico se hace cargo el propio Luis de Llera. En este caso nos encontramos con una aportación de primer orden, que se apoya en un acabado conocimiento de la situación de la filosofia espaniola en el momento del éxodo (situación sumamente feliz) y sigue con las aportaciones que los exiliados hicieron en muy diversos centros universitarios americanos. En estudios anteriores ya había llamado la atención Luis de Llera sobre el talante religioso, concretamente católico, de la mayoría de los principales filósofos exiliados y de su redescubrimiento de lo hispano (incluso de la "hispanidad") al conocer las dimensiones de la cultura iberoamericana in situ. Esto áltimo es objeto en este volumen de un estudio muy interesante sobre la búsqueda de una identidad para la filosofía del exilio.

Por fin, de las ciencias y de las artes se encarga Paola Laura Gorla, que trata además del cine español en Hispanoamérica. Muy interesante también.

Nos hallamos en suma ante una aportación de primer orden, que se añade ciertamente a una bibliografía muy copiosa pero que no sólo no desmerece en el conjunto sino que destaca por sus logros.

Algunos de esos expatriados se habian beneficiado antes de los trabajos de la Junta para Ampliación de Estudios, notable antecedente del Consejo Superior de Investigaciones

La Iglesía en la Encrucijada

Hispania Sacra 49 (1997) 
Científicas, y con ello tiene que ver el libro de Justo Formentín y de María José Villegas; se trata de una completa monografía acerca de una escuela de párvulos establecida en la vallisoletana Simancas y que funcionó como centro modelo en 1933-1937 y sobrevivió hasta 1947. Los autores la enmarcan en la evolución de la pedagogía parvularia europea y espafrola y en las tareas pedagógicas emprendidas desde la Junta de 1907 en adelante. En este último sentido, destaca como aportación del estudio la nómina que han elaborado los autores, de más de doscientos becados por la Junta para Ampliación de Estudios a lo largo de su historia con el fin de que desarrollaran estudios precisamente pedagogicos.

Entre los precedentes de la Escuela de Simancas, sobresale la labor del Instituto Escuela, desde 1918. También se examina, lógicamente, el mecenazgo de la historiadora norteamericana, protestante, Alice B. Gould, que vivió gran parte de su vida en España, trabajando sobre todo en los Archivos de Indias y Simancas para elaborar la lista de marineros que acompañaron a Colón. El conocimiento de la realidad educativa de Simancas la indujo a emprender y a financiar la obra del parvulario. En la vida de éste destacó su directora, la navarra Catalina Medina, que acabaría sus días como religiosa en una congregación católica. El estudio se basa en bibliografía, conversaciones y archivos, principalmente el de la propia Junta, que se conserva en Madrid, en el Consejo Superior de Investigaciones Cientificas.

Mientras tanto, desde 1936, se habían dado otras respuestas bien distintas a la persecución religiosa. Aquí, el libro de Alvarez Bolado. Conocíamos ya las entregas que había ido haciendo en Miscelánea Comillas de su estudio sobre la actitud del episcopado ante la guerra española de 1936-1939. Andando el tiempo, la suma de esos artículos, sin apenas cambios, se ha convertido en este libro, al que se le añade en apéndice el regesto de los escritos relativos a la guerra publicados en los Boletines episcopales de todas las diócesis españolas. Sólo este apéndice valdría la pena, pero claro es que la merece mucho más el libro en conjunto.

Alvarez Bolado opta al principio por una línea muy descriptiva: analítica, sí, pero muy pegada a los textos. Sería incluso prolijo el método si no lo requiriera el propósito último de la investigación, que es el que el autor declara en el prólogo: establecer los hechos para, sobre ellos, examinar la eclesiología de la guerra, por decirlo así: la vision episcopal como expresión de una eclesiología. Es importante tener esto en cuenta porque el libro no cubre, por lo tanto, más que la primera fase del estudio que el autor se ha propuesto.

Como consecuencia de ello, la narración combina la efemérides de la contienda militar con unas intervenciones en las que, inconscientemente las más de las veces, se conciliaba el propio ciclo de la guerra con el ciclo litúrgico.

Ya advierte el autor, también en el prólogo, que, mediada la investigación, se le ofrecí la posibilidad de emplear la documentación de la embajada española cerca de la Santa Sede y eso enriqueció el resultado pero también Jo desvió. Desde ese punto (sobre todo desde el quinto capítulo) las expresiones diplomáticas ganan terreno en detrimento de las manifestaciones episcopales; el libro, con ello, tiende a ser como otros libros y pierde algo de la originalidad del principio aunque gane en valor documental.

Seguramente, para la investigación hubiera sido tanto o más importante el empleo de los archivos diocesanos y, por razones obvias, el del cardenal Gomá, primado entonces de España. Quizá sea el momento de decir que hemos trabajado en él desde hace ya diez años y que, si los resultados de ese estudio (la edición crítica del archivo) no están al alcance de los investigadores, es porque, sistemáticamente, desde 1993, se nos ha negado la ayuda de 
la Dirección General de Política Científica y eso ha hecho que el trabajo (que aun así se ha emprendido y, Deo volente, empezará a ver la luz en breve) sea más lento de lo que sería deseable y posible contando con recursos. La última denegación venía acompañada de una justificación en la que se decía textualmente que ofrecíamos transcribir un archivo del siglo $\mathrm{XX}$, de valor desigual, y que para eso bastaba con microfilmarlo. El hecho, por lo insólito (y lo grave para el conocimiento de nuestra historia más reciente), merece que se sepa.

Sólo hasta cierto punto continúa la obra de Alvarez Bolado el libro de Verdera sobre la revista Ecclesia. Es fruto de una tesis de grado, según se aclara expresamente en la introducción. Se trata de otra pieza del mosaico de tesis y estudios varios que viene dirigiendo Gonzalo Redondo sobre la historia de la cultura política religiosa a partir de la Guerra civil.

En este caso (y en otros anteriores) la investigación que hay en la base del volumen se caracteriza por dos rasgos primordiales: se ciñe en gran medida al contenido estricto de la revista estudiada (claro que cotejado con la bibliografía más reciente) y sigue un orden expositivo rigurosamente cronologico. Esto da al estudio una sencillez y al tiempo una utilidad notables. Se resume en un conjunto grande de noticias sobre lo que fue sucediendo en la historia política y eclesiástica de España y su contraste con la visión que de ello había en los redactores de Ecclesia. El investigador de estas cosas encontrará, por tanto, buen número de datos de interés.

Como contrapartida, queda desdibujada la revista en sí, su papel en la vida española del período de que se trata (aunque el lector lo pueda deducir con claridad del conjunto del libro) y sobre todo se escapan todos los rasgos "duraderos" de la propia revista. No se habla de sus constantes, si las hubo, ni de las que pudiera haber en sus mentores.

Es éste al cabo el tributo que ha de pagar cualquier estudio exclusivamente cronologico, cuando se trata de una cronología de acontecimientos y no --además- de "coyunturas" y "estructuras", como diría algún intérprete de Braudel.

$\mathrm{El}$ otro tributo corresponde a la fuente. La vieja idea de que, en los siglos XIX y XX, "todo está en la prensa" (gracias a su multiplicación y a la libertad de expresión) se ha demostrado ya como algo falso. La prensa, como tantas otras cosas, era y es fruto de intenciones que se exponen en un lenguaje frecuentemente críptico y a veces equívoco o meramente sugerente. Cuando los hay, los archivos correspondientes a los sujetos que se estudian son un venero de noticias y aclaraciones que permiten entender de otro modo lo que se lee en los periódicos y, sobre todo, darle su verdadero alcance. Y el caso es que el archivo de Ecclesia existe, como demuestra alguno de los documentos que el autor reproduce en apéndice. ¿Por qué no lo ha empleado más? ¿Es que se trata de un archivo muy pobre o es que no ha tenido acceso a todo él? Al lector le queda esta duda.

Se refiere a los días de la segunda Guerra mundial. Que es también la época de la obra de Salaverri sobre Santiago Gapp. Por imperativos editoriales he leído este libro al tiempo en que leía el de Colm Tóibín sobre el catolicismo europeo actual. Y no me resisto a subrayar el contraste. Son dos libros contradictorios sobre un mismo asunto general: el hecho religioso y concretamente el católico. El segundo describe comportamientos colectivos; el primero, una trayectoria individual. En aquél, lo individual es secundario; necesariamente aparece, pero tan sólo como parte de lo colectivo; no hay más individualidad neta y destacada en el libro de Tóibín que la del propio narrador. En el de Salaverri, como contrapartida, hay importantes acotaciones sobre lo colectivo; llaman la atención sobre todo las actitudes ante el nacionalsocialismo (el antinazismo francés, la confusión que allí se daba entre alemanes y nazis) y, al lector español, le interesan especialmente las actitudes que descu-

La Iglesia en la Encrucijada Hispania Sacra 49 (1997) 
bre, en ese orden de cosas, en la España de la posguerra (aquí, el hermano de religión de Jakob Gapp que recibe a éste con el saludo Heil Hitler). Pero, en este otro libro, la biografía de un sacerdote marianista, todo eso sirve únicamente para dibujar el perfil de ese ser humano concreto.

Hay más contrastes. Ambas obras están escritas por católicos; pero Tóibín es un irlandés que perdió la fe de niño y el autor de la biografia de Gapp es un creyente hispano; ni uno ni otro ocultan sus posturas. Ciertamente, la densidad del catolicismo irlandés abruma, tal como Tóibín lo presenta (igual que abruma el catolicismo polaco del poscomunismo, un catolicismo omnipresente, agobiante, clerical y ajeno a lo íntimo). El catolicismo que se trasluce en la biografia de Santiago Gapp, en cambio, refleja el micromundo de una congregación religiosa entre tantas; también es clerical, pero lo es por đefinición - porque es cosa de clérigos-; el catolicismo seglar, cuando aparece, es mâs "normal" que el del irlandés, y eso que Tóibín habla de su niñez y del catolicismo de hoy y el biógrafo de Jakob Gapp se refiere en cambio a los afios treinta.

El principal contraste entre ambos libros estriba sin embargo en que Tóibín manifiesta una perplejidad y el Salaveri, una certeza. Y, eso no obstante, hay una lógica profunda que une los dos volúmenes.

A ver si soy capaz de explicarlo. El libro de Tóbin es un reportaje periodístico bien escrito. Narra, una detrás de otra, una serie de manifestaciones colectivas de fe: desde la recepción multitudinaria del Juan Pablo II en tal o cual lugar hasta las procesiones de Sevilla pasando por una peregrinación a Lourdes, una visita a Auschwitz y otros sucesos de este estilo. En cada uno de los casos se repite un esquema parejo y esto hace un punto reiterativa la lectura de la obra. Primero hay un viaje, el del periodista, y con ello la experiencia de un tren, un avión o un coche, una experiencia siempre levemente enojosa y siempre escépticamente aceptada; enseguida la llegada a un hotel, habitualmente insatisfactorio, y luego la inmersión del autor, como observador, en la manifestación colectiva de turno. Siempre, la aparición de sus recuerdos de niño, en Irlanda, como elemento de referencia más que de contraste: el resurgimiento, en último término, de aquello que un día perdió sentido para él.

El de Salaverri es en cambio una biografia de corte clásico. Trata de un religioso marianista austriaco, Jakob Gapp, que entendió pronto la íntima contradicción entre nazismo y cristianismo y lo manifestó expeditivamente allí donde le pusieron sus superiores: en público y en privado, más de una vez frente a los temores de sus propios hermanos de congregación. Sus superiores, para salvarlo de las iras de los agentes nazis, hubieron de llevarlo de país en país, primeno a Francia y después a España, esto último en 1939-1943, a poco de terminar la Guerra civil. En España encontró la admiración de muchos por lo germano y también el antinazismo de algunos, especialmente en la jerarquía eclesiástica: aquí, la instrucción pastoral antinazi que publicó e hizo leer en todas las iglesias de su díxcesis el obispo de Calahorra, Fidel Garcia, en 1941, en pleno éxito de Hitler. Al obispo le costaría Ja honra y la fama, que se preocuparon de mancillar falangistas y policías del Régimen ax̂os después. A Jakob Gapp (Santiago Gapp en España), su empeño en difundir ese documento terminaría por llevarlo a la guillotina, sacado de España con engaños por agentes de la Gestapo.

¿Dónde está la coherencia entre estos dos relatos? Tóibín no sale de su perplejidad ante todas y cada una de las celebraciones del culto católico a las que asiste. La perplejidad tiene una lógica para descubrir la cual no hay que ser adivino: desprovistos de fe, sin aceptar como algo lógico que otros seres humanos la tengan, esos actos carecen de sentido y sirven para mostrar el gregarismo y la mediocridad intelectual de los que creen en esas cosas. 
Tóibín tiene la delicadeza de no decirlo así pero su narración rezuma esa idea. En este sentido, la biografia de Gapp tendría que ser la biografia de la excepcion: entre tantos catolicos gregarios del antinazismo o del filonazismo, aparece de tarde en tarde un hombre de carácter entero y de ideas claras que se arriesga continuamente a decir la verdad.

Pues bien, no es así. Lo singular es que Gapp se nos descubre también como un hombre lleno de limitaciones: susceptible, irascible, descontentadizo, suspicaz, sensiblero, ahogado en nimiedades. El autor de su biografia nos ha hecho el favor impagable de no ocultarlo. Y, sin embargo, al salpicar continuamente su narración de citas de la declaración de Gapp ante el tribunal nazi que lo condenó a muerte, ese carácter débil contrasta, quizá sin que el autor se lo proponga, con la más rotunda entereza. Ante el tribunal, Gapp declaró punto por punto todo lo que quisieron saber que había hecho y sobre todo predicado en contra del nazismo. Sabía que iba a costarle la vida pero no se arredró.

Este es el punto al que Tóibín no ha acertado a llegar: no hay contraste entre una mayoría gregaria y la excepción original. La excepción sale de la mayoria. Más aún: forma parte de ella. Es decir. esos hombres que repiten ritos a los que no se les ve el sentido tienen además otras manifestaciones (tomán decisiones) que no son mediocres. Y algunos de ellos hasta asombran cuando las circunstancias se prestan. ¿Por qué? Eso hay que dejarlo para el lector de la biografia de Salaverri sobre Santiago Gapp y para el propio T6́ibín, si opta por continuar su indagación.

Anotaré en antepenáltimo lugar la aparición de la historia de la congregación de carmelitas misioneras teresianas, que vienen haciendo desde hace afios un esfuerzo editorial importante. S6́lo tiene que ver con los libros de que acabo de hablar el hecho de que llega hasta 1936. Es una historia clásica de una de las fundaciones del fecundo religioso exclaustrado Francisco Pajau Quer. El libro es una buena aportación documental a la historia congregacional, y fundamental, claro es, para la propia congregación.

Ramiro Viola ha acertado a evitar las apologías. La historia de la congregación fue rica en controversias y divisiones internas, que se nos relatan con detalle, sin rehuirlas. Incluso los intentos de reunificación del siglo XX terminaron por fracasar. En el fondo, Palau había diseffado una espiritualidad pero no una organización acabada, y esto lo notaron y sufrieron sus sucesores.

Hay, al respecto, páginas graves, como la de la escisión de la hermana Gratias y la compra del convento - jde su propiedad!- por mosén Verdaguer, que con ello comenzó su malaventura.

El episodio al que aludo tiene que ver por otra parte con la manera de disfrazar la propiedad congregacional; práctica habitual en las instituciones de la Iglesia tras la experiencia de la desamortización. En este caso recurrieron a nombrar abiertamente herederos a algunos religiosos o religiosas concretas, en lugar de que fuera la congregación la titular de la propiedad y la herencia. El problema es que, luego, hubo alguno que "hered6" en el sentido estricto y juzgó que podía conducir el correspondiente convento como patrimonio propio.

Otra cosa que llama la atención en el libro es la dependencia, sólo relativa, de la política. Ciertamente, los años de gobierno conservador permitieron la extensión del instituto. Pero no se puede pasar por alto el hecho de que su primera expansión se diera justamente en los años de la Revolución de Septiembre, 1868-1874.

La Iglesia en la Ercrucijada

Hispania Sacra 49 (1997) 
El libro, por lo demás, abarca desde los últimos años de la vida de Palau (el entorno de 1860) hasta la guerra de 1936 exclusive. Constituye, en suma, una pieza necesaria para la reconstrucción de la historia de la Iglesia en la España contemporánea.

Como lo es el de José Antonio Marcellán. En este caso nos hallamos ante una útil tesis doctoral de Ciencias de la Información. El origen de este libro está en una encuesta lanzada desde el semanario diocesano pamplonés La Verdad en 1979 por el autor, que entonces lo dirigía. De un lugar de Navarra llegó la lista de todos los hijos del pueblo que habían seguido la vocación eclesiástica, hombres o mujeres; se planteó "quién đa más" $\mathrm{y}$, a partir de ello, la respuesta de los párocos, principalmente, fue unánime y decisiva para la elaboracíón de lo que aquí se presenta como apéndice del libro: la nómina alfabética de todos los eclesiásticos navarros vivos el primero de enero de 1980, hombres o mujeres, clérigos y legos. A partir de esto, el autor hizo un intento de explicación de la dinámica vocacional que se deducía de los datos, empleando principalmente la prensa regional (y sus propios recuerdos y los de otros sacerdotes), y el resultado es este libro.

Su importancia deriva de la importancia que ha tenido en la Iglesia, hasta el entorno de 1970, la dícesis pamplonesa desde el punto de vista de las vocaciones. Su crisis, por lo mismo, es de vital importancia para la historia de la Iglesia. Y esto precisamente ocupa una parte importante del libro.

El autor distingue cuatro etapas en los cincuenta años a que se refiere el libro: la de siembra vocaciones, entre 1936 y 1947; la de crecimiento, entre 1947 y 1967 (que es la época de plenitud), la crisis de los años setenta y "El alba que tarda en Ilegar", o sea el comienzo de la recuperación, que, la verdad, tan sólo es un indicio de los últimos años.

El estudio lleva consigo un conjunto importante de cálculos muy variados: sobre el seminario, sobre la vitalidad vocacional de cada una de las comarcas de Navarra y acerca de los institutos de perfección preferidos, en el caso de los religiosos. Abundan los gráficos.

La obra ha sido objeto de alguna crítica estimable. Véase al respecto la de Juan María Lecea, publicada en Diario de Navarra el 8 de octubre de 1996. A nuestro juicio, no procede sin embargo - -en una valoración puramente profesional como es la que debemos hacer desde estas páginas - entrar en si la interpretación de los hechos es o no acorde con el punto de vista del crítico. Tiene que serlo con el del autor, por puro sentido común, y eso basta. De las críticas, por lo tanto, sólo podemos hacernos eco del error de cálculo que se ha introducido según Lecea al buscar el porcentaje de seminaristas que legaron a ordenarse, por haber sumado al parecer todos los alumnos de todos los cursos año tras año, sin pensar que, al cursar cada alumno varios años, la cifra resultante está muy equivocada.

En lo demás, es una obra imprescindible para la historia reciente de la Iglesia, en España y fuera de España. Como lo son las Confesiones del cardenal Vicente Enrique y Tarancón, concernientes en buena parte al mismo periodo de que trata Marcellán.

Las coordenadas, sin embargo, son distintas. En este caso se trata, por lo pronto, de unas memorias. Los editores insisten en que no son tales y en que puede haber, por lo tanto, unas memorias estrictas. Pero lo cierto es que no cabe encuadrar estas páginas en otro género.

No se esperaba su publicación, tan cercana a la muerte del prelado y, relativamente, a los hechos que narra. Se suponía que, de existir este texto, tardaría en aparecer, como es costumbre en los libros de esta naturaleza, especialmente en los eclesiásticos. Pero aquí está. La obra se refiere a los años que van de la consagración de Tarancón como obispo de Solsona en 1945 al final de 1975, inmediatamente después de la muerte de Franco. 
Se ha escrito que es una narración excesivamente política, sin referencias de carácter sobrenatural. $\mathrm{Y}$ lo peor es que no es verdad. Si lo fuera, podríamos pensar en que el autor tuvo la intención đe escribir un relato de su actuación política, tan importante desde 1971, y que dejó para otra ocasión o para otra pluma su actuación como obispo. Pero no es así y eso induce a pensar que es que, en efecto, Tarancón actú́ como obispo hasta 1971 y se dejo ganar por la política (o creyó conveniente dedicarse a ella preferentemente) desde esa fecha. Las páginas dedicadas a los años 1945-1971 son claramente "episcopales": describen actuaciones de esa naturaleza y constituyen por ello un buen testimonio de cuáles eran las preocupaciones y, en parte, las ocupaciones de un obispo de aquellos años. De esa parte, nos interesa ante todo la explicación que cabe encontrar de la voluntad que tuvo Pablo VI hacia 1971 de encumbrar a Tarancón a la cabeza de la Conferencia Episcopal española y al arzobispado de Madrid. Fue una voluntad demasiado visible para pasar desapercibida al historiador. ${ }_{i}$ Cuándo y por qué se fijó el Papa en la personalidad del obispo de Solsona? No hay una respuesta clara en estas páginas pero nos ha llamado la atención la noticia de la reunión de prelados de Espaffa y Francia en 1957 (pág. 190 y siguientes). Habíamos notado ya la importancia que pudo tener en el encumbramiento del prelado levantino la amistad y en cierto modo la protección que le brind6 Casimiro Morcillo, arzobispo entonces de Zaragoza, en cuyo palacio recalaba don Vicente de paso hacia Madrid y donde sabíamos se reunían personajes de cierta relevancia del clero francés y francófono. Suponíamos que allí debió de conocer Tarancón figuras que pudieron servir para que Pablo VI se formara una alta idea del prelado y, en efecto, allí se celebraron las conversaciones hispanofrancesas a que acabo de referirme y allí se detenía con frecuencia según sus Confesiones:

Desde las páginas concemientes al entorno de 1971, el libro se centra abrumadoramente en la política. La transición la marca con cierta claridad la Asamblea Conjunta, que se celebró entonces y que ocupa en el libro una extensión muy amplia. Incluso se repiten a veces los datos con una reiteración excesiva, prolija. Hay ocasiones en que puede hablarse de una verdadera repetición de la narración en sí. Se ve que el texto no pudo ser revisado por el autor como era menester. Si lo hubiera hecho, lo hubiera aligerado desde luego y, sin duda, habría evitado esas reiteraciones, que dejan la impresión de provisionalidad de lo escrito.

El hecho es que, desde 1971, las Confesiones se convierten en un relato de maniobras políticas, en las que el confesante, por cierto, siempre tiene razón y siempre atina.

Esto último es lo de menos. Por digno de crédito que sea el memorialista, como sucede en este caso, el historiador está obligado a contrastar su testimonio con el de otros y así tendrá que hacerlo quien emplee estas Confesiones como fuente. Cosa que tendrá que hacer quienquiera que estudie ese período de la historia de España.

Otra cosa es que el libro haga aportaciones fundarnentales. No las hace. Añade mil detalles pero el fondo interpretativo es el que ya se dejo ver hace años en las conversaciones con Tarancón que publicó Martín Descalzo.

De esta parte política del libro, lo más original (y desalentador, ya diré más adelante por qué) es la idea que el arzobispo tuvo del Opus Dei y el protagonismo que le adjudica. Como es sabido, los planteamientos de la Asamblea Conjunta (sobre los que ya hemos expresado algunas ideas favorables en Los españoles, entre la religión y la politica: El franquismo y la Democracia, Madrid, Unión Editorial, 1996) fueron rechazados en Roma; Tarancón ya había insinuado que fue labor de gente de la Obra y aquí no solo lo repite sino que expresa la completa certeza de que fue el Opus Dei el que intentó inutilizar la Asamblea por no decir sabotearla.

La Iglesia en la Encrucijada Hispania Sacra 49 (1997) 
En este afirmación ya hay un paso adelante que empieza a suscitar el desaliento al que me he referido. Durante toda su historia, la gente del Opus Dei, empezando por su fundador, el beato Escriva, ha insistido en que se trata de una institución (hoy una prelatura personal) sin otro fin que el estrictamente espiritual de la mejora de sus miembros y sin otra acción corporativa que la de la formación doctrinal y la atención espiritual de sus miembros y cooperadores. Ciertamente, tanta insistencia, durante tanto tiempo y por parte de tantas gentes de buena voluntad, debería dar que pensar a una persona que, como Tarancón, se movía también por la buena fe. Pues bien, algo tan sencillo como esto no lo entendia o no lo aceptaba ni siquiera el primado, luego arzobispo de Madrid. Toda la segunda mitad de sus Confesiones están atravesadas por la idea implícita pero palmaria de que lo que dice que hacían tales o cuales personas (Lopez Bravo y Lopez Rodo sobre todo) era el Opus Dei. Y esto no es baladí, ni -por tratarse de quien se trata- puede considerarse como una incomprensión entre tantas. Por el contrario, contribuye a explicar las deficiencias de la forma en que una parte de la jerarquía eclesiástica española entendía el papel del laicado, que parecía reducir a la lectura durante la misa (enseguida, también a dar la comunión). Esto es: se consideraba ese papel como antaño: como colaborador, si no sustituto, de los presbíteros. Y esto era desalentador porque, en la coyuntura de la Iglesia del siglo XX, equivalió a esterilizar una parte fundamental de su posible acción evangelizadora.

Digámoslo sin miedo: Tarancón no entrevió la trascendencia -al menos hasta saber llevarla a la práctica- - de la constitución Gaudium et spes. Quedó anclado en la mentalidad propia de la Acción Católica, de la que había sido consiliario. Institución venerable que ha tenido un papel fundamental en la historia de la Iglesia preconciliar y pudo tenerla en la posconciliar, la naturaleza de AC era no obstante la de instrumento secular de la jerarquía eclesiástica y nada más. Su crisis, a mi juicio, también tuvo que ver con el hecho de que sus dirigentes no entendieron el papel atribuido a los laicos en el Concilio Vaticano II. Creyeron que consistía en sustituir a los obispos: esto es en continuar con el paraguas protector de la Iglesia (en todos los sentidos, también en el relativo a la justicia y el derecho penal, en el caso de Espafia) pero sin supeditarse a la jerarquía.

Tarancón llega a afirmar del Opus Dei "que su ascética individual y su sentido de cristiandad les hace considerar al poder político y las riquezas como los instrumentos más eficaces de evangelización" y "que, como consecuencia de este convencimiento, que yo considero sincero, ellos estaban abiertamente comprometidos con el Régimen y tenían en él una gran influencia; y promovían la riqueza entre los suyos" (pág. 489). Más adelante añade que es que el Opus Dei no aceptaba el Concilio Vaticano II.

La verdad es que, al hablar de que ellos estaban abiertamente comprometidos con el Régimen, Tarancón no se acuerda de que, en los mismos días de que habla, se estaba desarollando la importante singladura del diario Madrid, en la que intervinieron bastantes miembros del Opus Dei y que constituyó una de las acciones de oposición más firmes al Régimen. Como es obvio que también el arzobispo habla en sus Confesiones con el mismo convencimiento sincero que reconoce en los demás, hay que preguntarse por qué ignora ese hecho. Y la explicación -que presumo, sin más evidencia que el mero cálculo de probabilidades- es la de que el diario Madrid no intervino en los pleitos eclesiásticos que narra Tarancón. En el fondo, este lector se teme que Tarancón creyera que, con sus maniobras politicas, estaba evangelizando, y lo demás (por ejemplo, oponerse al Régimen desde un plano estrictamente laico) era cosa ajena a la Iglesia. $O$ sea que olvidaba que todo lo que es verdadero es cristiano, aunque no se llame así, según la sabida ecuación agustiniana. 
Respecto al rechazo del Concilio Vaticano II, no hace muchos meses, al preparar Los españoles, entre la religión y la política, estudié expresamente ese aspecto en la prensa inspirada o redactada por miembros del Opus Dei y me sorprendió (porque no era la hipótesis de la que partía) la densidad de textos de formación espiritual y doctrinal de los años sesenta basados explícitamente en las encíclicas de Juan XXIII y Pablo VI y en los documentos oficiales del Concilio. Me llamó la atención la especial y reiterada atención que se prestaba al decreto sobre la libertad religiosa, claro que aceptándolo y basando en êl las exhortaciones que allí se hacian. En algunas revistas, además, se daba noticia con entusiasmo de decenas de reuniones de estudio de los documentos conciliares que se estaban celebrando en aquellos días. Lo que dice Tarancón no se sostiene.

Por último, la referencia a la consideración del poder político y de las riquezas como instrumentos de evangelización de máxima eficacia. Emplé las memorias de Tarancón como fuente especialmente digna de fe en Los españoles, entre la religión y la política. Por otra parte, algunas cosas que he escrito en ese libro han hecho que fuera silenciado en unos casos y criticado en otros, precisamente en varias revistas dirigidas por gente de la Obra. Es justo, además, preguntarse qué parte de error corresponde a los miembros del Opus Dei para que pueda darse -especialmente en un arzobispo- un dislate como ése. No soy capaz de improvisar una respuesta. Pero no tengo duda de que tiene su tanto de culpa la actuación de algunas personas de la Obra de particular notoriedad en la vida pública y acadérnica. El caso de quienes elaboraron la crítica de los documentos básicos de la Asamblea Conjunta de martas, si fue en efecto gente de la Obra como asegura Tarancón, es un modelo de torpeza y de miopía: hicieron de los mismos una lectura sesgada, propia de la cultura de sospecha que tanto se ha ejercido contra el Opus Dei y contra tantas otras instituciones de la Iglesia.

Pero las cosas son como son. He oído cientos de homilias, meditaciones y charlas de gente de la Obra, además de un sinfin de conversaciones. He leído gran parte de la literatura que le atañe. Lo he escuchado todo con el aguzado, quizás hipersensible sentido crítico que Dios me ha dado. Jamás he oído nada que tenga que ver con esa barbaridad de la riqueza y el poder político de que habla el cardenal en sus Confesiones. Y dudo que el cardenal lo oyera. Si no, no se comprendería que él fuera quien abrió el proceso de beatificación de Josemaría Escrivá; no se entendería tampoco que autorizara en su propia dícesis la multiplicación de centros del Opus Dei, siendo así que la aprobación expresa y escrita del ordinario era y es preceptiva para la erección de cada uno de esos centros; sería inverosímil que no se lo hubiera hecho ver a Pablo VI, quien desde luego no pensaba así, según otras fuentes. Etcétera etcétera.

Visto así, y sabido que el libro no cambia lo que ya conocíamos sobre los años 19451971 , los albaceas, herederos y editores de Tarancón quizás hubieran hecho mejor en seguir el ejemplo de los hijos de Noé.

La Iglesia en la Encrucijada

Hispania Sacra 49 (1997) 